\title{
Self Help Groups (SHGs) and Women's Development: A Case Study of the Varanasi District, India
}

Tripti Kumari ${ }^{\dagger}$ and Anand Prasad Mishra ${ }^{++}$

\begin{abstract}
Development is a multi-dimensional process that affects society in multiple ways. It is well documented that women constitute about half of the world's population but their share in the economy and other development spheres remain neglected. In addition, this large section of population (including Indian women) have been suffering from various disadvantages - lack of accessibility to resources, non-recognition of their economic contribution within the family and society. In order to resolve these emerging challenges, Government of India (GOI) has implemented various programmes and policies since Independence. Among these programmes, Self Help Groups (SHGs) may be considered as a significant initiative of the government as well as the non-governmental organisations (NGOs). These are based on the principle of democratic process of development. The democratic institution provides a platform to the socially and economically deprived sections and encourages them for economic participation. Since the 1970s, SHGs have been working in many states of India and contributing to the development processes. The present paper is an attempt to analyse the contribution of SHGs in women's development in the district of Varanasi in Uttar Pradesh. The impact of these groups on women's development has been analysed by Gender Development Index (GDI), which focused on the male-female differences in terms of longevity of life, knowledge and economic betterment.
\end{abstract}

Key words: Development, Self Help Groups, Women in Development, Varanasi, India

\footnotetext{
${ }^{+}$Research Scholar, Department of Geography, Banaras Hindu University, Varanasi, Email: sweety.lata00@gmail.com

${ }^{+\dagger}$ Professor, Department of Geography, Banaras Hindu University, Varanasi, Email: adeepayan@gmail.com (C)2015 Kumari and Mishra. This is an Open Access article distributed under the terms of the Creative Commons Attribution License (http://creativecommons.org/licenses/by/2.0), which permits unrestricted use, distribution, and reproduction in any medium, provided the original work is properly cited.
} 


\section{Introduction}

There is a large literature on the impact of Self Help Groups (SHGs) and the collective strengthening of the communities living in poverty (Banerjee, 2009; Desai and Joshi, 2013; Narasaiah, 2008; Sinha, 2008; Sreeramulu, 2006; Sugunu, 2011). However, none of the previous studies has investigated the economic betterments gained from the SHGs in the city of Varanasi, Uttar Pradesh. The key aim of this research, therefore, is to analyse the contribution of the SHGs in women's development in the district of Varanasi. For this, we use Gender Development Index (GDI) to analyse the impact of these groups on women's development, which focuses on the male-female differences in terms of longevity of life, knowledge and economic betterment.

It is worth noting here that it was Ester Boserup, a Danish economist in the 1970s, who was the first to debate about women's role in economic development. She is considered as an advocate of Women in Development (Boserup, 1974; also, Bhattacharyya, 2009). However, even in the 21st century, development policies continue to be biased against women.

Development studies in contemporary developing economy like India have put forward many new aspects for academic discourses. The crude sense of economic development has failed to meet the aspiration of the individual and society at many levels, which needs fresh attention in our policy framework and social sciences research. The on-going development policies are shaping our entire social, economic, cultural and political spheres of lives. The dynamics of these development policies have attracted scholars, policymakers and development agencies to search out a scientific method for the analysis of different components of development and its layering process in under-developed social and economic structures. In this direction, the concept of human development has emerged as an initiative that is proposed by the United Nations Development Programmes (UNDP), which is a suitable methodology to examine the spatial pattern of development in a specific geographical location. The 1990 Human Development Report (HDR) has made detailed observations on this and discussed it in a scientific way. This well designed- HDR is based on three basic components of development-education, standard of living and income which unfold the social and spatial inequalities across the globe. This report has opened up new frontiers in academics and development discourses but social and spatial inequalities remain. Seemingly, in 2012, the World Bank published the World Development Report (WDR) that focuses on the economics of gender equality and development. It argues that gender equality enhance economic opportunities and productive inputs to generate income for both men and women. This report also emphasises on providing a space where men and women have equal chance to receive education, health, access to economic opportunities and productive resources and the ability to make effective choices and take action. (WDR, 2012: 6). Earlier, Myrdal (1984) observed that in order to achieve greater equality and economic growth, it is necessary to raise the miserable living status of the poor masses instead of radical institutional reforms. (World Bank Publications, Pioneers in Development page no. 154). The evolving debate on issues of social justice and channelisation of the large chunk of population of marginalised section into mainstream development activities are combined with many socio-cultural realities. The UNDP's Human Development Concept draws attention to the fact that the goals of human development cannot be achieved without the development and empowerment of women. In the said context, the 1995 HDR, of UNDP introduced two new indices. These are Gender Development Index (GDI) and Gender Empowerment Measures (GEM). The GDI adjusts the average achievement in each of the three dimensions calculated in the HDI, to account for the inequalities between men and women. These three indicators are health, income and education. HDI and GDI are tools that can be used to identify deep-rooted gender based-inequities and, thereby, demand 
implementation of policies, programmes and schemes that would help achieve equitable development outcomes.- (Human Development Indices: Recasting GDI and GEM for India, 2009)

In a familial context, WDR (1991) emphasised its focus on challenges of contemporary development, which needs to improve the quality of life of the marginalised sections of societies. However, a better quality of life is generally considered not as a product of higher income but it includes much more - that is, better educational facilities, higher standards of living, improved health care facilities, employment opportunities for all, food for all, a cleaner environment and opportunity for a sustainable future. In continuation of a development with people's welfare, the studies in HDR (2010) also urged for more peoplecentric development. This report articulated the concept of human development as enlarging people's choices, which lead to a long and healthy life, to be educated and to enjoy a decent standard of living (HDR, 2010: 12). In principle, these choices can be infinite and can change over time. Development is observed in terms of per capita income, which is not suitable for people's well-being, so it should focus on greater access to knowledge, better nutrition and health services, more secure livelihoods, security against crime and physical violence, satisfying leisure hours, political and cultural freedoms and sense of participation in community activities. The objective of development is to create an enabling environment for people to enjoy long, healthy and creative lives (Mahbub ul Haq 1991: 17 and 19). The proposed concept of development attracted policy makers and researchers to critically examine the one-sided approach for material production rather than to improve quality of life and opportunities for common people. Amartya Sen (1998) has also put forward this on-going welfare approach to development as tools of social justice and observed human development as enhancing the capabilities, freedom and rights of individuals, rather than the richness of economy. Against these backdrops, the present paper is an attempt to examine the impact of
SHGs on women's development in Varanasi, a holy city located on the banks of the river Ganga in Uttar Pradesh. In the next section, we discuss the dimensions in women's development.

\section{Evolving Dimensions in Women's Development}

Contemporary development studies focus its attention on gender equality, which tries to find out a way for an alternative model for sociocultural progress. This emerging dimension in development strategy redefines the policies and paradigms and prepares the ground for reorienting our research in social sciences that can fulfil the aspirations of the different social hierarchies of our society. The prevailing spatial and socio-cultural structure in any developing economy has significantly played its role in (re)shaping the process of formation over a space. Consequently, gender bias in social structure is a bi-product of our past productive tools that proved its suitability in favour of the male sex. In male-dominated social structures, women development programmes needs special attention by the development agencies, which trace the routes of gender deprivation. Although, various agencies are trying to understand these aspects of socio-cultural realities, however, the question of gender equality and development still needs attention. In spite of several attempts by development agencies and social organisations, women are facing many problems at the level of family and society. Therefore, development programmes are shifted towards women, children and people of backward social groups. Moreover, in underdeveloped social organisation, the scaling of gap between male and female marked highly unequal, and it reflects its negative consequences in the areas of education, employment and health. The prevailing nature of inequalities creates social hierarchies and conflict among various vulnerable populations. Women have always remained deprived in the development process, which has now become a serious subject in social sciences (Bhattacharyya, 2009, 2013). 
In the Indian context after Independence, the policy makers had realised that the agenda of modernisation would be completed through participation of women in production and decision-making process. To achieve this, various welfare plans for development of women were started by the Government of India (GOI); however, it could not be implemented at the ground level. Based on the ground reality, most of the women development schemes tried to follow a suitable concept of bottom-up level approach. In continuation to this, SHGs has emerged as a medium to organise women of similar locality and socio-economic background. It has been observed from various studies that although these women are poor and illiterate, yet they have different kinds of traditional skills such as stitching, weaving, pickle making, etc. These groups are promoting women for small and regular savings and also providing loan to its members on demand. By utilising such loans, women have started small shops at their homes, contributing economic benefits to their families (Figure 5). Such loans have also enabled them to develop entrepreneurship at small scale, based on their traditional skills. The Self Employed Women's Organization (SEWA), Gujarat, deserves mentioned for its successful efforts in mobilising large numbers of poor selfemployed women in their road to empowerment, which has not only enhanced the level of self-confidence among the women but also strengthened their financial position (SEWA Report, 1972). SEWA was started in 1972 , as a trade union for women in the unorganised sector. Today, SEWA boasts for running the first women's bank in India. SEWA has also linked up many co-operatives and has emerged as the largest federations of the cooperatives in the country. A report submitted to the erstwhile Planning Commission reveals that the rate of success of the SHGs are more in Andhra Pradesh and Gujarat than in Uttar Pradesh and Bihar (VOICE, Report 2008). This report highlights the spread of awareness through education and NGO in the areas. The following section discusses the impact of SHGs on women's development.

\section{SHGs and Women's Development}

Initially, most of the welfare programmes supported the unprivileged groups of society, especially the vulnerable sections, which include Scheduled Castes (SCS), ${ }^{1}$ Scheduled Tribes (STs) ${ }^{2}$ and women. Recently, many steps have been taken to concentrate and strengthen the policies of self-help, especially for women in the unorganised or the informal sector. SHG has evolved through long observation of various past outgoing policies and strategies for welfare of the deprived sections of population. SHG is a concept based on the homogeneity, mutual support, group approach and regular savings. It serves the principle "by the women, of the women and for the women". It evolved through the essence of Gandhian philosophy of economic development, aims at "Gram Swaraj" norm that means: of the people, by the people and for the people. "All for all" is the principle behind the concept of SHGs. (Suguna, 2011: 16). SHG is a small economically homogeneous affinity group of rural poor, who are voluntarily ready to contribute for a common fund which is lent to its members as per the group's decision that works for the group's solidarity, self-help, awareness, social and economic empowerment in a democratic way. Today, SHGs are emerging as powerful tools of poverty alleviation and enable the society to improve the quality of life of the group members through mobilisation of human resources, especially for women. Initially, SHG emerged from the concept of Grameen Bank of Bangladesh founded by Mohammad Yunus in the year 1976. He observed that credit is the base for the

\footnotetext{
1"Scheduled Castes" means such castes, races or tribes or parts of or groups within such castes, races or tribes as are deemed under article 341 to be Scheduled Caste for the purposes of this constitution.

2 The term "Scheduled Tribes" first appeared in the Constitution of India. Article 366 (25) defined Scheduled Tribes as "such tribes or tribal communities or parts of or groups within such tribes or tribal communities as are deemed under Article 342 to be Scheduled Tribes for the purposes of this constitution". Article 342, which is reproduced below, prescribes procedure to be followed in the matter of specification of Scheduled Tribes.
} 
development of any country, and SHG in developing countries serve as a medium of micro-credit provision and support the target group in the following ways:

- Creates confidence and mutual support among the members.

- Prepares forums where women can critically analyse their situation and advice collective strategies to overcome difficulties.

- Act as a platform for creating awareness, training, capacity building, dissemination of information and delivery of services and for developing communal self-reliance and collective action.

- Construct vehicle for promotion of economic activities. (Mennai, 2003: 168).

Various studies on SHGs and women's development provided inputs about the significance of the approach to gender equality, especially for those women who are engaged in unorganised economic activities. The capacity building measures for individuals and society, advocated by Amartya Sen (1991) supported the genuineness of SHGs in a developing society. UNDP, through its various efforts, recognises poverty alleviation programme and is mostly based on self-initiative by the concerned sections of the population. On this account, SHG became a powerful mediator to poverty eradication and subsequent enhancement of women's capabilities. Moreover, SHG also provides space for the vulnerable sections of women by extending opportunities for saving, facilitating formation of social capital and overall background for furthering the process of self-help and entrepreneurship.

Our research observes that after joining the SHGs in Varanasi, the status of women have improved considerably and through the programmes of SHGs, women are contributing to their families in particular and Varanasi society in general. Women, who belong to the lowest economic sections of the society are not in the position to save huge amount of money in the banks but SHGs provide them the place where they can save small amount of money and receive credit at a very low rate of interest, lesser than the local moneylenders (see also, Bujar Baruah, 2014; Lahiri-Dutt and Samanta, 2013). Group approach and collective responsibilities are the two keys behind the success of these groups. With the establishment of National Bank for Agricultural and Rural Development (NABARD) in the 1990s, the concept of SHGs has come into existence and has been successful in the development of women.

\section{Objectives}

As stated earlier, the key objective of this paper is to explore the impact of SHGs on the development of women in Varanasi district. To study this, the calculation of GDI has been made for scientific observation of grounded problems. The Gender Development Index (GDI) is a composite indicator that measures the development of states according to the standard of living in a country. GDI is developed by the UN, and it is used as one of the five indicators by the UNDP in their annual HDR. It highlights inequalities in the areas of long and healthy life, knowledge, and a decent standard of living between men and women (Please refer to Gender Development Index [GDI] Law \& Legal Definition, available at: http://definitions.uslegal.com/g/genderdevelopment-index-gdi/).

GDI and GEM were both developed by the UNDP in its 1995 HDR report. It focused on the difference of long and healthy life, knowledge, and a decent standard of living between men and women. Under the National Rural Livelihood Mission Plan of the GOI, about 1800 SHGs had been organised in the Varanasi district as of March 2014.

\section{Database and Methodology}

Geographically, Varanasi district lies between $25^{\circ} 10^{\prime}$ to $25^{\circ} 37^{\prime}$ North latitudes and $82^{\circ} 39^{\prime}$ to $83^{\circ} 10^{\prime}$ East longitudes. Its major areas are stretched towards the West and North of the Varanasi district. The total geographical area of 
Varanasi district is 1535 sq. km. embracing a total population of $3,676,841$ (male and female population are $1,921,857$ and $1,754,984$ respectively as per the 2011 Census). Administratively, the district comprises two tehsils - Pindra and Varanasi, which are further sub-divided into eight development blocks namely: Baragaon, Pindra and Cholapur in Pindra tehsil and Chiraigaon, Kashi Vidhyapeeth, Araziline and Sevapuri in Varanasi Sadar tehsil. Harahua block lies in both the tehsils. The southern and south-eastern part of Harahua block is under Varanasi tehsil but its major part lies in the Pindra block. Varanasi district, situated on the left bank of the river Ganga, is located between river Ganga in the south and river Gomati in the north, while the Varuna river flows in the central part of the district. The city occupies almost a central position in the Ganga valley. Figure 1 shows the location map of the study area.

As stated above, the objective of this research is to develop a gender-related composite index on the basis of household data of the members of the SHGs. In order to unravel the ground reality of gender gap in Varanasi, this paper deals with multiple indices of gender development based on U.N. norms, that is, GDI and GEM. Through international scaling of GDI and GEM, micro level reality of underdeveloped region could be focused in social science research. Both GDI and GEM owe its origin to Human Development Index (HDI) precursor, which is derived on the basis of three main components-per capita income, education attainment and life expectancy (an indicator of healthy life). The GDI is defined as a "distribution-sensitive measure that accounts for the human development impact of existing gender gaps in the three components of the HDI" (Klasen, 2006: 243). In this research, the GDI of the members of SHGs at the household level have been calculated by composite index of education, income and life expectancy (at the age of more than 40 years). For this purpose, field study was conducted and data has been collected through questionnaire schedules. A total of 340 samples had been selected from different development blocks of
Varanasi districts, namely, Baragaon, Sevapuri, Kashi Vidhyapeeth, Pindra, Chiraigaon, Cholapur, Harahua, Araziline and the city area of Varanasi. The survey was based on purposive and stratified sampling method. The data obtained from the field has been further processed using SPSS 20 software, Microsoft Excel 2010, and a map has been generated using Arc GIS 9.3 software. Data has been classified at the household level for male and female separately. In order to find out the gender gap, that is, male-female differentials, all these indicators have also been calculated. After that, the processed data has been tabulated into different groups based on education, per capita monthly income and age of more than 40 years. Following this, the data has been standardised through index value, which ranges between 0 and 1 . Index value is calculated by the formula (Vi-Vmin)/ (VmaxVmin), where, $V i$ is the actual value, $V \max$ is the maximum value and $V \min$ is the minimum value in the given data series.

\section{Geographical Perspective: A Micro-level observation}

As discussed above, this study is based on the primary data collected from the field survey of different development blocks of Varanasi district. The study unfolds that SHGs in Varanasi provides an opportunity to the women in the district. Varanasi is located in the eastern part of Uttar Pradesh. Like many metropolitan cities of India, it suffers from illiteracy, unemployment, poverty and many other problems. This study shows that in the district there are many SHGs organised for the rural women who are the major neglected sections of the society. Considering all the issues of women and development, this research is an attempt to explain the impact of SHGs on women's development in the geographical space of Varanasi. In the district of Varanasi, SHGs were formed and managed by both the Government as well as Non-Government Organisations (NGOs). For our research, we have undertaken SHGs founded by the two NGOs, namely, World Literacy of Canada and Lok Chetana Samiti and one Government SHG 
constituted under the National Rural Livelihood Mission (NRLM). Therefore, on the micro-level analysis, we observed that these small groups are working for the development of women in the region. Women in SHGs of Varanasi collectively work in a number of activities, such as poppadum, pickle making, weaving (Varanasi silk), tailoring, etc. Figures 3 and 4 show women working in groups, while Figure 5 illustrates a woman working in her petty shop. These activities reveal that the three SHGs in Varanasi have been working as an aid to salvage women from extreme forms of poverty. These women now feel more confident and are economically better when compared to their lives prior to joining SHGs -a key towards positive development. The findings of this research support the idea that SHGs are the lifeline for these women (Banerjee, 2009; Desai and Joshi, 2013; Narasaiah, 2008; Sinha, 2008; Sreeramulu, 2006; Sugunu, 2011). In a slightly different context, these findings also bear resonance to the study conducted by Bhattacharyya and Vauquline (2013) on the impact of Mahatma Gandhi Rural Employment Guarantee Act on poor women of Assam living in multiple forms of poverty.

\section{LOCATION MAP}
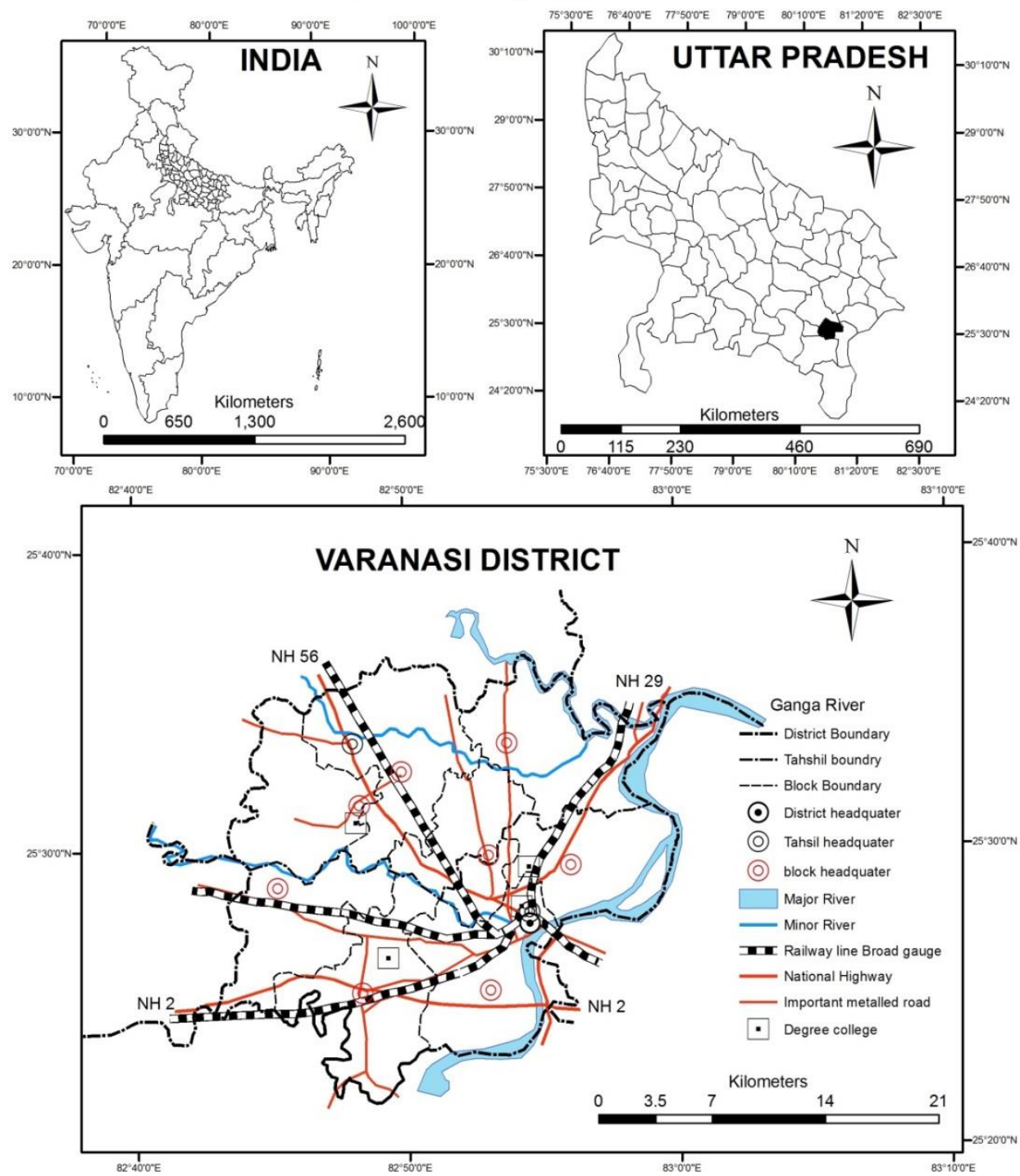

Figure 1 


\section{Table 1: Spatial Dimension and Its Pattern (Block wise Average Monthly Income of Household Level,}

Varanasi District)

Development Blocks
Average monthly income of male (₹/ Month)
Average monthly income of female (₹ / Month)
Average monthly income of male- female differentials

\begin{tabular}{ccccc} 
& (₹/ Month) & (₹/ Month) & $\begin{array}{c}\text { differentials } \\
\text { (₹ / Month) }\end{array}$ & \\
\hline Varanasi City & 7720 & 1852 & 5868 & 0.48 \\
\hline Sevapuri & 6490 & 872 & 5618 & 0.42 \\
\hline Baragaon & 6362 & 1058 & 5304 & 0.34 \\
\hline Pindra & 9380 & 2100 & 7280 & 0.80 \\
\hline Harahua & 5067 & 1278 & 3789 & 0 \\
\hline Araziline & 7137 & 1750 & 5387 & 0.36 \\
\hline Chiraigaon & 8572 & 2421 & 6151 & 0.24 \\
\hline Cholapur & 8111 & 3250 & 4861 & 1
\end{tabular}

\section{Source: Based on Personal Field Survey, 2013-2014}

Apparently, this research reveals gender inequality in terms of monthly income. This is reflected in Table $1-$ the spatial patterns can be explained through its multiple databases that have been obtained from field study. Economic benefits through SHGs in terms of monthly income represent gender gap in the study area. In this context, Table 1 reveals the gap between male-female incomes, which is highest in Kashi Vidhyapeeth block (₹ 8135), followed by Pindra ( $₹ 7280$ ) and Chiraigaon ( $₹$ 6151) blocks while Harahua block (₹ 3789) has minimum gender gap. On the other hand, the gap between male and female monthly income is medium in Varanasi city ( $₹ 5868$ ), Sevapuri ( $₹$ 5618), Araziline ( $₹ 5387$ ) and Baragaon ( $₹ 5304$ ) blocks. As discussed above, in order to demonstrate spatial pattern of income, index value for male-female differential has been calculated with the formula given below:

Index value: (Vi-Vmin)/ (Vmax- Vmin)

Where, $\mathrm{Vi}$ is the actual value, Vmax is the maximum value and $V \min$ is the minimum value in given data series.

The expectancy of life (more than 40 years) is a scientific criterion for scaling the level of health and human resources development. Expectancy of life (more than 40 years) in a vulnerable section of society can be used as a positive indicator of health status. Table 2 shows the spatial pattern of life expectancy of more than
40 years with male-female differentials. The analysis reveals that there is a prevalence of health-related gender inequality in the study area. The obtained value unfolds that the malefemale gap in expectancy of life more than 40 years is highest in the Varanasi city area, which is 16 years, followed by Harahua (9 years) and Sevapuri (8 years) while this is lowest in the Pindra block (4 years). This pattern of gender gap reflects the poor quality of health and nutritional status of the women in the Varanasi district. Our study also reveals that due to lack of awareness and illiteracy, their accessibility to health and nutrition schemes remain very poor. The result reflects that the government programmes for the development of women's health like; maternity benefit schemes, immunisation schemes, etc. are not implemented at the ground level, as a result of which women of the study area remain deprived.

Knowledge as a resource is another important indicator for the analysis of gender development. -Table 3 reveals the spatial pattern of gender gap in literacy in the study area. Gender gap in literacy shows the differences in the level and the extent of education between males and females (here, among these vulnerable sections in Varanasi). Data reveals that this gap is maximum in Kashi Vidhyapeeth block, that is, 10.38 per cent 
Table 2: Distribution of Population more than 40 Years of Age at the Household Level

\begin{tabular}{ccccc}
$\begin{array}{c}\text { Development } \\
\text { Blocks }\end{array}$ & $\begin{array}{c}\text { Number of Males } \\
(\geq 40 \text { years })\end{array}$ & $\begin{array}{c}\text { Number of Females } \\
(\geq 40 \text { years })\end{array}$ & $\begin{array}{c}\text { Difference between Males } \\
\text { and Females }\end{array}$ & $\begin{array}{c}\text { Index } \\
\text { value }\end{array}$ \\
\hline Varanasi City & 89 & 73 & 16 & 1 \\
\hline Sevapuri & 18 & 10 & 8 & 0.33 \\
\hline Baragaon & 17 & 11 & 6 & 0.16 \\
\hline Pindra & 31 & 27 & 4 & 0 \\
\hline Harahua & 16 & 7 & 9 & 0.41 \\
\hline Araziline & 19 & 12 & 7 & 0.25 \\
\hline Chiraigaon & 19 & 14 & 5 & 0.08 \\
\hline Cholapur & 23 & 16 & 7 & 0.25 \\
\hline Kashi & 17 & 12 & 5 & 0.08
\end{tabular}

Vidhyapeeth

Source: Based on Personal Field Survey, 2013-2014

\section{Table 3: Blockwise Distribution of Literacy at Household Level}

Development Blocks Male $\quad$ Female $\quad$ Male-Female Difference Index Value

\begin{tabular}{cccccccc} 
& No. & $\%$ & No. & $\%$ & No. & $\%$ & \\
\hline Varanasi City & 319 & 91.40 & 318 & 87.12 & 1 & 4.28 & 0.18 \\
\hline Sevapuri & 65 & 86.67 & 75 & 82.40 & 10 & 4.25 & 0.17 \\
\hline Baragaon & 81 & 88.0 & 49 & 81.67 & 32 & 6.37 & 0.46 \\
\hline Pindra & 103 & 97.14 & 88 & 90.72 & 17 & 6.42 & 0.46 \\
\hline Harahua & 73 & 89.0 & 52 & 79.69 & 21 & 9.33 & 0.85 \\
\hline Araziline & 87 & 91.5 & 78 & 88.64 & 9 & 2.93 & 0 \\
\hline Chiraigaon & 86 & 93.4 & 78 & 86.67 & 8 & 6.80 & 0.51 \\
\hline Cholapur & 102 & 92.0 & 75 & 83.33 & 27 & 8.56 & 0.75 \\
\hline Kashi Vidhyapeeth & 71 & 90.0 & 62 & 79.49 & 9 & 10.38 & 1
\end{tabular}

Source: Based on Personal Field Survey, 2013-2014

followed by Harahua (9.33 per cent) and Cholapur blocks (8.56 per cent), while in the Araziline block, the gender gap in literacy is minimum (2.93 per cent). On the other hand, in Varanasi, the gender gap in literacy is 4.28 per cent. The prevalence of knowledge gap justifies the effort of better quality and universalisation of education. This universalisation of education is definitely a rational approach to minimising gender gap.

In addition, we have also calculated the malefemale differences for each indicator. All indicators were standardised by the abovediscussed formula in index value, and then a composite index has been prepared based on average value. The maximum and minimum composite value ranges between 0.20 and 0.69 .
The data on GDI (male-female differences) explains the prevalence of gender discrimination in the study area and reflects the poor status of women. Table 4 and Figure 2 reveal the spatial pattern of GDI through composite index of all observed indicators in different blocks of Varanasi district. The GDI value divided into three groups that is, low $(0.00-0.35)$, medium $(0.35-0.50)$ and high $(0.50-0.70)$. The spatial patterns of GDI reveals variation in different blocks and its patterns are: Varanasi city (0.55) and Kashi Vidhyapeeth (0.69) blocks with high GDI value; Cholapur (0.41), Pindra (0.42), Harahua (0.42), Baragaon (0.32) and Sevapuri (0.31) blocks reveal medium GDI, while Araziline (0.20) and Chiraigaon (0.38) blocks show low GDI. 


\section{Table 4: Blockwise Distribution of Composite Index Value at Household Level}

\begin{tabular}{ccccc} 
Development Blocks & \multicolumn{3}{c}{ Index value } & $\begin{array}{c}\text { Composite Index } \\
\text { Value (GDI) }\end{array}$ \\
\cline { 2 - 5 } & Age above 40 & $\begin{array}{c}\text { Average Monthly } \\
\text { Income }\end{array}$ & Literacy & 0.55 \\
\hline Varanasi City & 1.00 & 0.48 & 0.18 & 0.31 \\
\hline Sevapuri & 0.33 & 0.42 & 0.17 & 0.32 \\
\hline Baragaon & 0.16 & 0.34 & 0.46 & 0.42 \\
\hline Pindra & 0.00 & 0.80 & 0.46 & 0.42 \\
\hline Harahua & 0.41 & 0.00 & 0.85 & 0.20 \\
\hline Araziline & 0.25 & 0.36 & 0.51 & 0.38 \\
\hline Chiraigaon & 0.083 & 0.54 & 0.75 & 0.41 \\
\hline Cholapur & 0.25 & 0.24 & 1 & 0.69
\end{tabular}

Source: Based on Personal Field Survey, 2013-2014

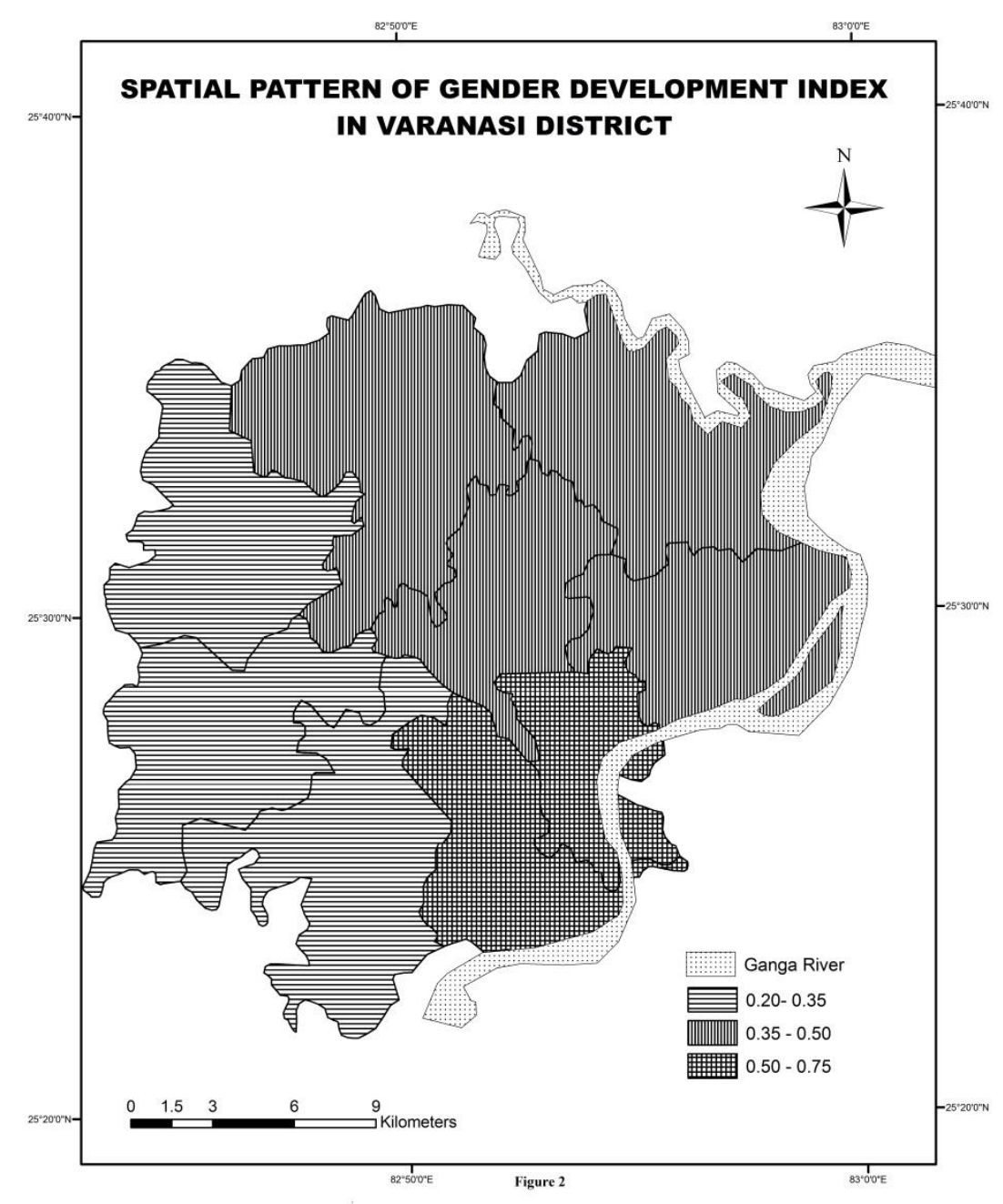

Figure 2 
The concentration of high GDI value explains that urban infrastructural and cultural environment have created positive opportunities for women's empowermentthe research reflects that through the SHGs, these women are excelling in the traditional skills like weaving, pickle making, tailoring, cooking, etc. However, they lack capital and modern techniques of knowledge. Nonetheless, there is evidence to suggest that their bargaining power have increased and have boosted their confidence. In addition, this research shows that these SHGs have enhanced their awareness skills, the culture of entrepreneurship and participation in the dynamics of decision-making processes. These results match those observed in earlier studies (Banerjee, 2009; Desai and Joshi, 2013; Narasaiah, 2008; Sinha, 2008; Sreeramulu, 2006; Sugunu, 2011).

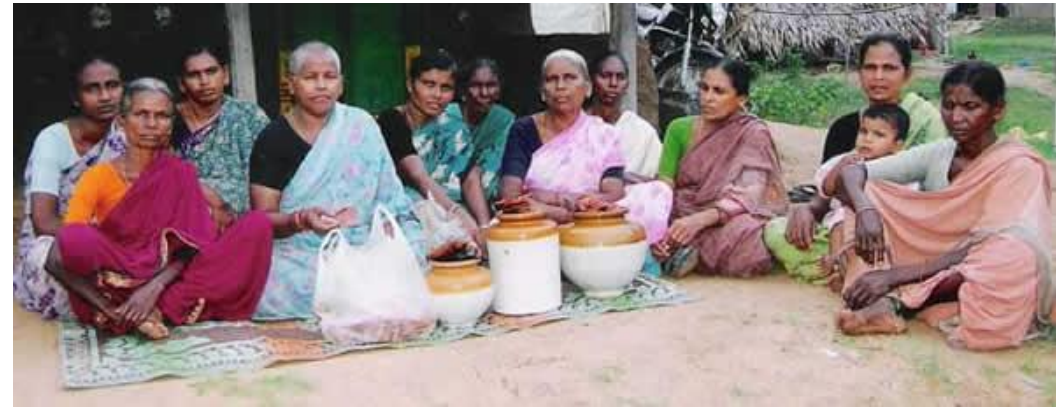

Figure 3: Women Collectively Making Pickles

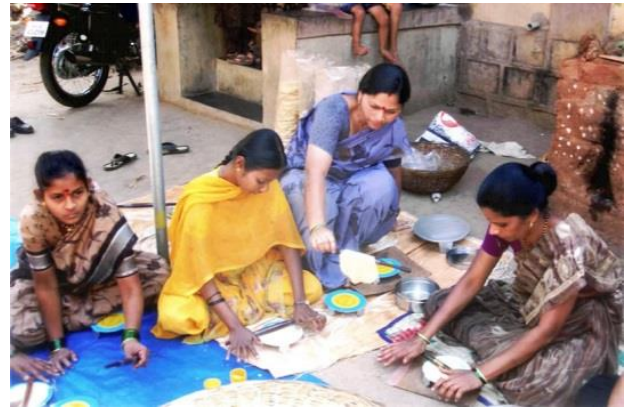

Figure 4: Women Collectively Making Poppadum

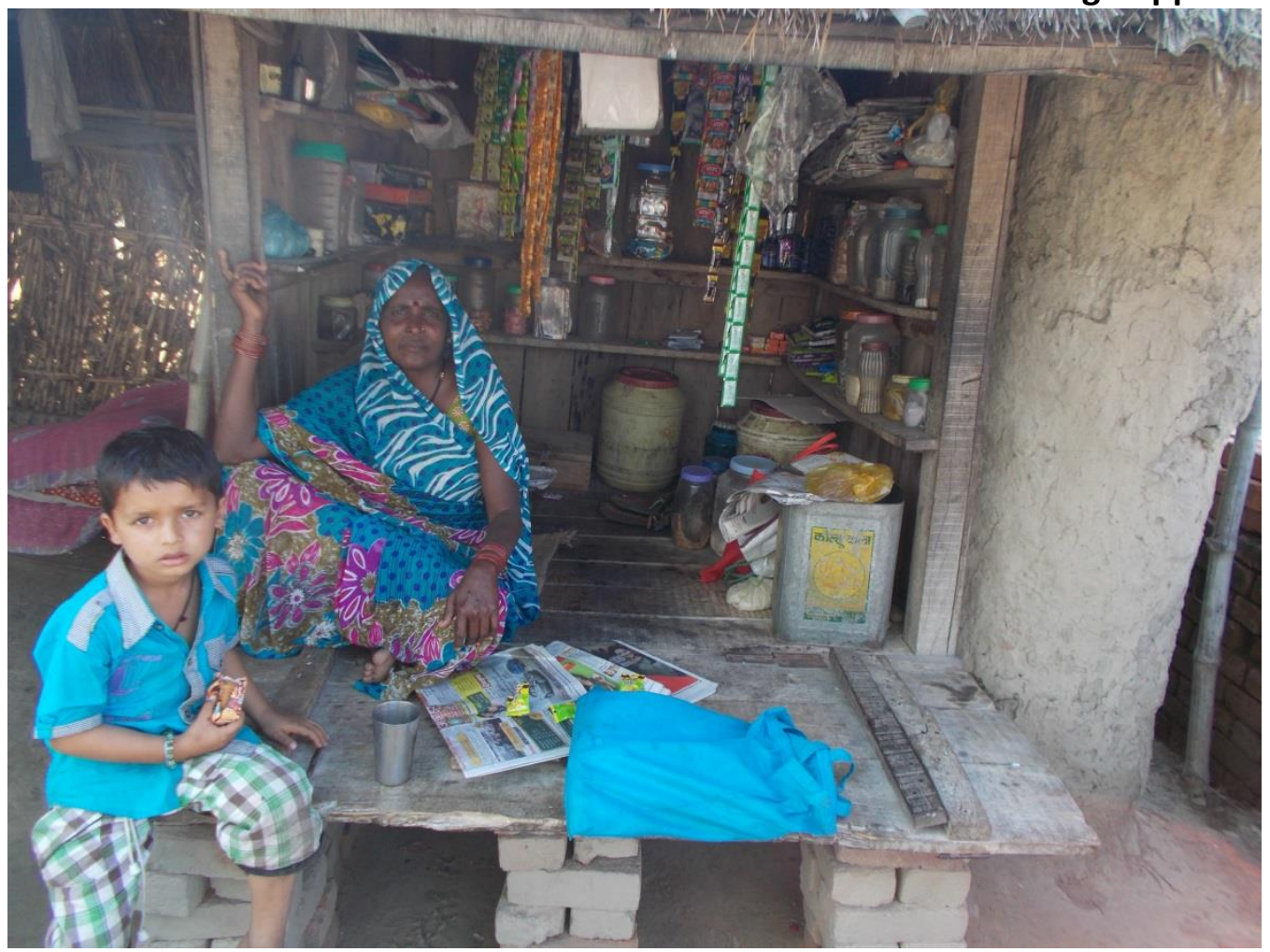

Figure 5: Woman Working in Her Petty Shop

\section{Conclusion}

From the field observations and data analysis, it can be concluded that women in the Varanasi district have substantially benefited from the
SHGs. It is observed that SHGs are playing a significant role for betterment of women and gender empowerment. In addition, these SHGs are providing platforms to these poor women to build their capacities and thereby, self- 
empower themselves. This would lead the path towards the power of decision-making both at the household level as well as at the group level. The study further supports the observations of Mennai (2003) and put forward the following: SHG creates confidence, prepares platform to create awareness among them and construct vehicle for promotion of economic activities among the deprived sections of women.

\section{References}

A Report on the Success and Failure of SHGs in India: Impediments and Paradigms of Success, 2008, Voluntary Operation in Community and Environment (VOICE), New Delhi.

Arunachalam, J. and Kalpagam, U., (2006).Development and Empowerment: Rural Women in India, Rawat Publications, Jawahar Nagar, Jaipur, India, ISBN: 81-316-0014-9

Banerjee, T. (2009). Economic Impact of SelfHelp Groups: A Case Study, Journal of Rural Development, 28, (4), 451-467.

Bhattacharyya, R. (2013). Are We Empowered? Stories of Young Indian Working Women, Saarbrücken, Germany: Lap Lambert Academic Publishing, ISBN: 978-3-659-20580-4

Bhattacharyya, R. (2009). Examining the Changing Status and Role of Middle Class Assamese Women: Lessons from the Lives of University Students, PhD thesis, Newcastle University, UK

Bhattacharyya, R. and Vauquline, P. (2013). A Mirage or a Rural Life Line?: Analysing the Impact of Mahatma Gandhi Rural Employment Guarantee Act on Women Beneficiaries of Assam, Space and Culture, India, 1(1), 83-101, ISSN: 2052-8396

Bhowmik, K. (2006). Indian Women: The Ushering of a New Dawn, Mittal Publications, New Delhi, India.

Boserup, Ester. (1974). Women's Role in Economic Development, The Bangladesh Economic Review, 2(1), 507-510.

BujarBaruah, Prasenjit. (2014). Financial Access of Unorganised Manufacturing Enterprises in
Assam, Journal Space and Culture, India, 2 (2), 4-16.

Chandra, Susmita. (2001). Women and Economic Development, B. R. Publishing Corporation, Delhi.

Datta, Rekha. (2003). From Development to Empowerment: The Self-Employed Women's Association in India, International Journal of Politics, Culture, and Society, 16 (3), 351-368 Deneulin, S. and Shahani, L., (2009). An Introduction to the Human Development and Capability Approach: Freedom and Agency, International Development Research Centre, London.

Desai, Raj M. and Joshi, Shareen. (2013). Collective Action and Community Development, Policy Research Working Paper, 6547, World Bank.

Felice, F. William, (2003). The Global New Deal Economic and Social Human Rights in World Politics, New Delhi Millennium Books in International Studies. Rowman and Liitlefield Publishers, Inc. Maryland, United Kingdom.

Gendering Human Development Indices: Recasting GDI and GEM for India 2009, Ministry of Women and Child Development, GDI and UNDP, Report

Gerald, M. Meier and Dudley, Seers, (1984). A World Bank Publication, Pioneer in Development, Oxford University Press.

Human Development <accessed on 10/11/2014> Web: http://hdr.undp.org/en/humandev.

Human Development Report, 2010, 20 ${ }^{\text {th }}$ Anniversary Edition, "The Real Wealth of Nations: Pathways to Human Development, UNDP.

Kabeer, N. (2005). Gender-Equality and Women's Empowerment: A Critical Analysis of the Third Millennium Development Goal, Gender and Development, 13(1).

Klasen, S. (2006). UNDP's Gender-Related Measures: Some Conceptual Problems and Possible Solutions. Journal of Human Development, 7(2), 243-274. 
Kanmony, J. Cyril. (2010). Dalits and Tribes of India, Mittal Publications, New Delhi, ISBN: 8183243487

Kavitha, A. and Nagaraj, G.H. (2011). Women Empowerment through SHG:- A Case Study. Southern Economic Journal, Golden Jubilee Year, pp. 9-12.

Lahiri-Dutt, Kuntala and Gopa S. (2013 How Do The Poor Handle Money? What Do The Financial Diaries of Char Dwellers Tell Us about Financial Inclusion, Journal Space and Culture, India, 1 (1), 43-57.

Mathew, P.M., The Non-Governmental Development Sector in India: Structure, Linkages and Opportunities, Institute of Small Enterprises and Development (ISED). Cochin.

Meier, M. Gerald and Seers Dudley, (1984). A World Bank Publication: Pioneers in Development, Oxford University Press.

Meenai, Zubair, (2003). Empowering Rural Women: An Approach to empowering women through credit based Self Help Groups, Aahar Books, New Delhi.

Narasaiah, M. Lakshmi, (2008). Microcredit and Women, New Delhi: Discovery Publishing House Pvt. Ltd.

Parr, F.S. and Kumar, A.K. Shiva, (2004). Readings in Human Development: Concept, Measures and Politics for a Development Paradigm, Oxford University Press, Business and Economics, New Delhi. 2nd edition.

Prasad, K. (2006). Women in Rural Development: Contemporary Social Policy and Practices. New Delhi: The Women Press.

Rahman, Z. (2005). Women and Society, Delhi: Kalpaz Publications.

Sen, Amartya. (1993). Capability and Wellbeing, The Quality of life, Oxford University Press, pp. 30-53.

Sen, A. K. (1999a). Development as Freedom. Oxford: OUP.

Sen, A. K. (1999b). The Possibility of Social Choice, American Economic Review, 89(3), 349378.
Sen, Amartya. (2001). Economic Theory Freedom and Human Rights: The Works of Amartya Sen, London: Overseas Development Institute, Briefing Paper.

Sengupta, Keya. (2010). Ed. Human Development, Multi-Dimensional Approach to Human Well-being, Concept Publishing Company, Pvt. Ltd., New Delhi, pp. 5.

SEWA 1972, Annual Report, Ahmedabad, India: SEWA

Shivalingappa, P. and Nagaraj G.H., (2011). Women Empowerment and Gender Equality: A Study. Southern Economic Journal, Golden Jubilee Year, pp. 15-17.

Sinha, D., (2008). Self-Help Group: Vehicle for Women Empowerment: A Study in the BolpurSantiniketan Community Development Block of Birbhum District. Indian Journal of Social Development, 8 (1), 123-136.

Sreeramulu, G. (2006). Empowerment of Women through Self Help Groups, Delhi: Kalpaz Publications, ISBN: 81-7835-501-9

Suguna, B. (2011). Empowerment of Rural Women Through Self Help Groups. New Delhi: Discovery Publishing House, ISBN: 81-8356-0962

World Development Report 1991, The Challenge of Development, World Development Indicators, World Bank, Oxford University Press.

World Development Report 2012, Gender Equality and Development, The World Bank, Washington, DC.

\section{Acknowledgement}

We are highly grateful to the anonymous reviewers for their valuable suggestions and comments on an earlier version of this paper.

\section{About the Authors}

Tripti Kumari is a Research Scholar. She obtained her MA degree in Geography in 2010 from the Department of Geography, Banaras Hindu University (BHU). She has also qualified UGC NET in Geography and UGC NET in Population Studies. She has also done one-year Certificate Course in Statistical Methods 
organised by the Department of Statistics, B.H.U. and six-month certificate course in Rural Development organised by IGNOU. She also published a research paper in NGSI Journal and also presented paper in many national and international conferences and attended orientation programmes, workshops on Research Methodology. She is an ICSSR Doctoral Fellowship awardee. Her area of interest is Women and Empowerment. She is a life member of National Geographical Society of India.

Dr. Anand Prasad Mishra is a Professor in the Department of Geography, B H U. He obtained his M.Sc. in 1979 and Ph.D. in 1985 from B.H.U. Earlier he worked as a Research Associate (U.G.C, 1990-2001) in the same department. He was also an Honorary Fellow and Project Coordinator in Gandhian Institute of Studies, Rajghat, Varanasi, UP from 2003 to 2005. He has published more than 55 research papers, four books and two co-edited books on different relevant themes. His major fields of interests are rural poverty, resources, development studies, gender and medical geography. Dr Mishra has also completed three projects on rural and tribal poverty, one research monograph on agrarian poverty at micro level and reports on Naxal movement, which got recognition from policy makers and social activists. His project on "Sishu Mandir and Madaras Education in Eastern UP: An Evaluation in National Integrity" sponsored by Ministry of HRD, New Delhi has put substantial material for policy makers towards the process of secular orientation in education. He has attended several national and international conferences, including two conferences in Mexico, Rio de Janeiro and Brazil. He is a life member of NAGI, NGSI, LLG and Eastern Geographical Society. 